\title{
Timing and Synchronization (Tutorial/Overview)
}

\author{
Krzysztof Czuba
}

Warsaw University of Technology

Institute of Electronic Systems

\author{
LLRF09
}

KEK, Tsukuba, 21.10.2009 


\section{Tutorial Objective}

- Give an overview of techniques used for synchronization systems

- Create some order in basic concepts of synchronization (practice shows that they are often confused even by LLRF team people)

- Indicate the most important issues of synchronization subsystems (without going into details) 


\section{Definition of Synchronization}

1. Synchronization is timekeeping which requires the coordination of events to operate a system in unison

2. The relation that exists when things occur at the same time

The synchronization is performed with use of signals readable by components of the system

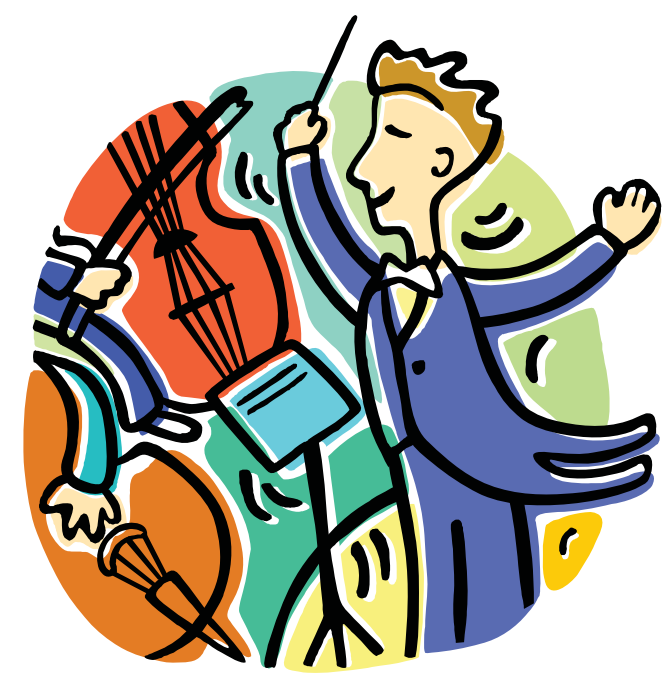




\section{Accelerator Synchronization - Overall}

Generic layout of a FEL facility

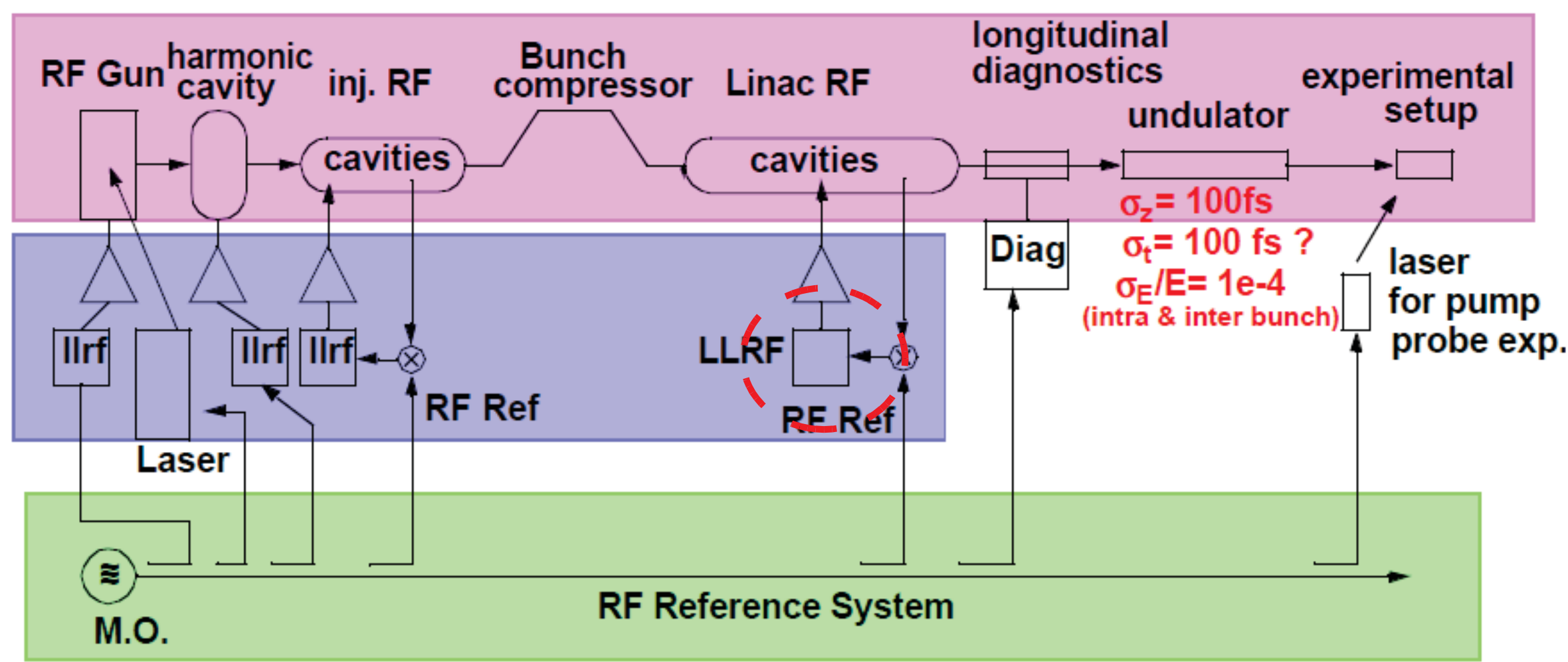

Accelerator subsystem must "play" together at the same time on order to achieve desirable acceleration of particle beam (beam energy and time parameters) and SASE 


\section{Local Synchronization (LLRF)}

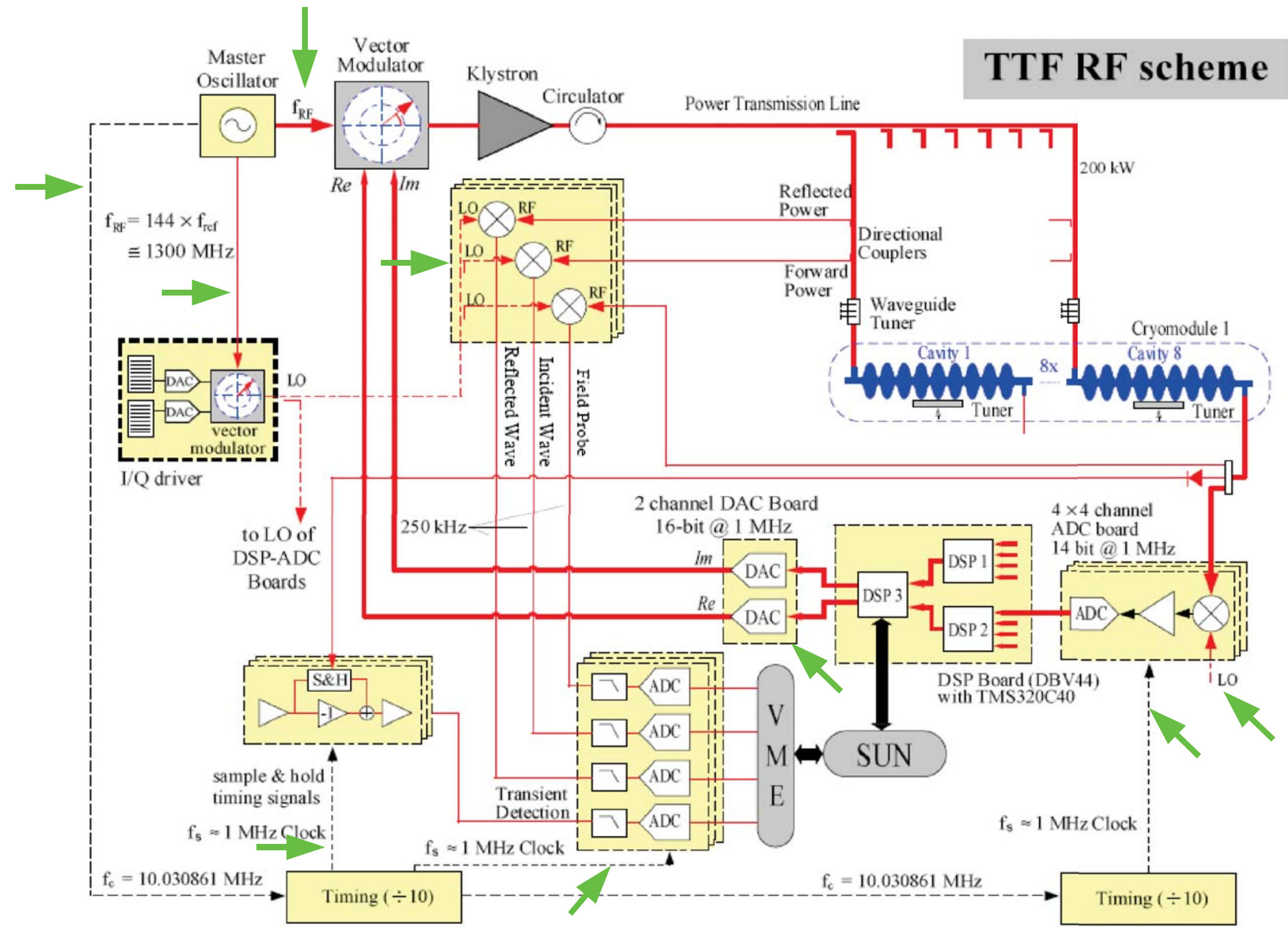

Figure source: Thomas Schilcher, "Vector sum control of pulsed accelerating fields in Lorenz force detuned superconducting cavities" 


\section{Synchronization Signals}

- Analog (RF phase reference, VM, LO)

- Clocks (digital subsystems, ADC, DAC, CPU)

- Trigger signals (digital subsystems, CPU)

- Optical signals (lasers, diagnostics, experiments) 


\section{Phase Reference vs Clock}

People often confuse:

- Phase Reference Signal: RF (MO) harmonic signal

- Clock: "digital" signal in common standard like CMOS, LVDS,... 


\section{Synchronization System}

Consists of:

- Master Oscillator

- Phase Reference Distribution (for harmonic RF signals)

- Timing System (for clocks and triggers) 


\section{RF vs Optical Synchronization}

The $\mathrm{MO}$ and phase reference distribution can be realized either in RF technology or in optical (laser oscillators and synchronization)

- RF:

- mature technology

- well known subsystems

- limited performance (but sufficient for many applications)

- sensitive to EMI

- Optical:

- low loss, easier installation (fiber as media)

- promising performance (sub-fs accuracy estimated)

- still under development - reliability not proven

- future projects 


\section{Harmonic Signal With Noise Components}

In Time Domain

$$
\begin{aligned}
& \text { Ideal Signal } \\
& \mathrm{v}(\mathrm{t})=V_{0} \sin \left(2 \pi v_{0} t\right) \\
& \text { Noisy Signal } \\
& v(t)=\left[V_{0}+\varepsilon(t)\right] \sin \left[2 \pi v_{0} t+\phi(t)\right]- \\
& V_{0}-\text { the nominal peak voltage amplitude } \\
& v_{0}-\text { nominal frequency, called also instantaneous } \\
& \varepsilon(\mathrm{t}) \text { - deviation of amplitude from nominal value } \\
& \phi(t) \text { - deviation of phase from nominal value - noise component }
\end{aligned}
$$

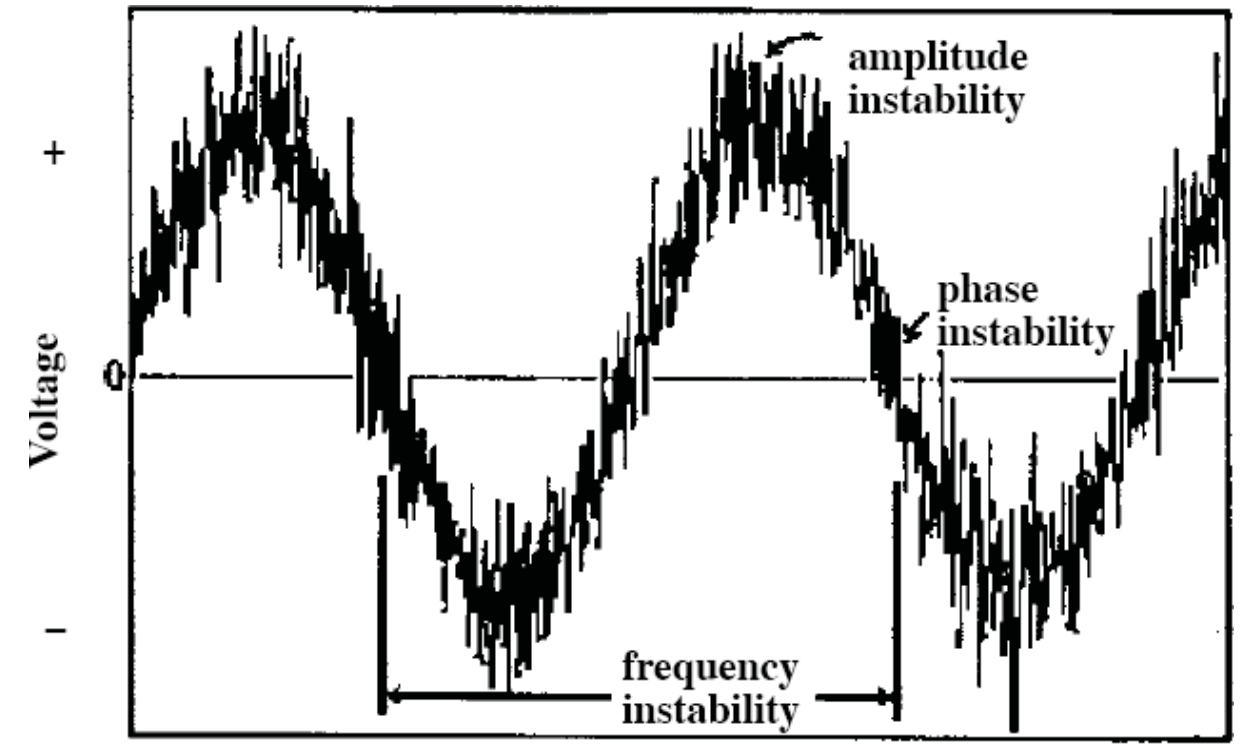

Time 


\section{Frequency, Time and Angle - Basic Relationships}

Why do you use "ps" when you talk about phase??

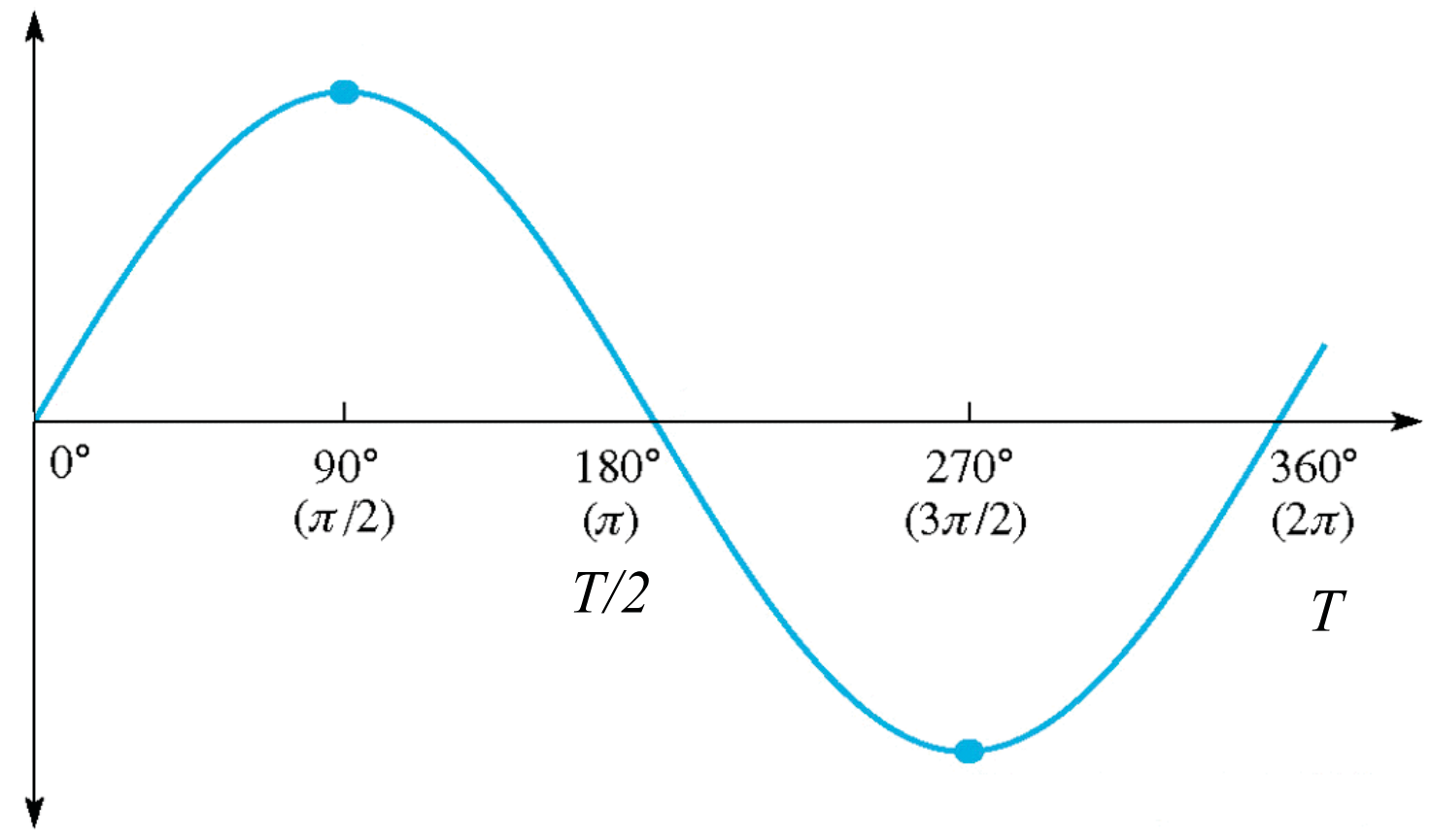

$$
\begin{aligned}
& T=\frac{1}{v_{0}} \quad \begin{array}{l}
\text { Time domain } \\
\text { measure }
\end{array} \\
& T \rightarrow 360^{\circ} \text { in the angular domain } \\
& t=\frac{\phi T}{360^{\circ}} \quad \begin{array}{l}
\text { Phase to time } \\
\text { conversion }
\end{array}
\end{aligned}
$$

Example: $v_{0}=1.3 \mathrm{GHz} \rightarrow T=\sim 769 \mathrm{ps}, 1^{\circ} \rightarrow 2,13 \mathrm{ps}$

Time domain measure is convenient for phase changes in distribution media (by means of propagation delay change) because it does not depend on the signal frequency. 


\section{Frequency and Phase Instability}

The instantaneous frequency of a signal with phase noise component

$$
v(t)=v_{0}+\frac{1}{2 \pi} \frac{d \phi(t)}{d t}
$$

Definition of the frequency instability

$$
y(t)=\frac{v(t)-v_{0}}{v_{0}}=\frac{1}{2 \pi v_{0}} \frac{d \phi(t)}{d t} \quad \begin{aligned}
& \text { This quantity characterizes the } \\
& \text { instantaneous frequency deviation } \\
& \text { from the nominal frequency }
\end{aligned}
$$

The phase instability expressed in units of time

$$
x(t)=\frac{\phi(t)}{2 \pi v_{0}}
$$




\section{Short and Long Term Instabilities}

The short-term instability refers to all phase/frequency changes about the nominal of less than a few second duration.

- derives from a "fast" phase noise components $(f>1 \mathrm{~Hz})$

- expressed in units of spectral densities or timing jitter

The long-term instability refers to the phase/frequency variations that occur over time periods longer than a few seconds

- derives from slow processes like long term frequency drifts, aging and susceptibility to environmental parameters like temperature

- expressed in units of degree, second or ppm per time period (minute, hour, day ...) 


\section{Phase Noise}

It is a frequency domain measure of signal phase instabilities $\phi(t)$

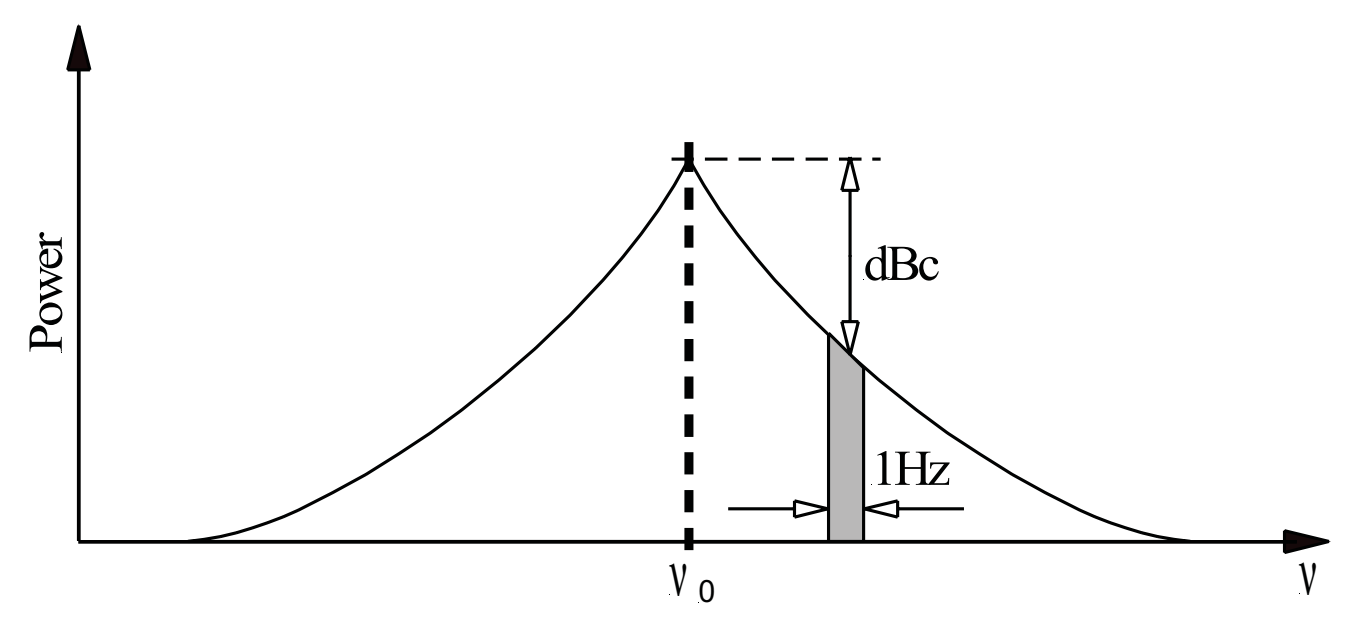

Power Spectral Density measured in $\mathrm{dBc} / \mathrm{Hz}$

$$
\begin{gathered}
\begin{array}{c}
\text { power density inone } \\
\text { phase noise modulation } \\
\text { sideband, per } H z
\end{array} \\
\mathscr{L}(f)=\frac{1}{2} S_{\phi}(f) \\
f=v-v_{0} \text { offal signal power from the carrier frequency }
\end{gathered}
$$




\section{Absolute and Residual Instabilities / Noise}

The absolute instability refers to the total phase noise present at the output of the signal source or a system.

The relative instability refers to a measure between different points of a system. It is mostly caused by residual noise and phase drifts of a distribution media.

Relative stability type is of high importance for the synchronization systems

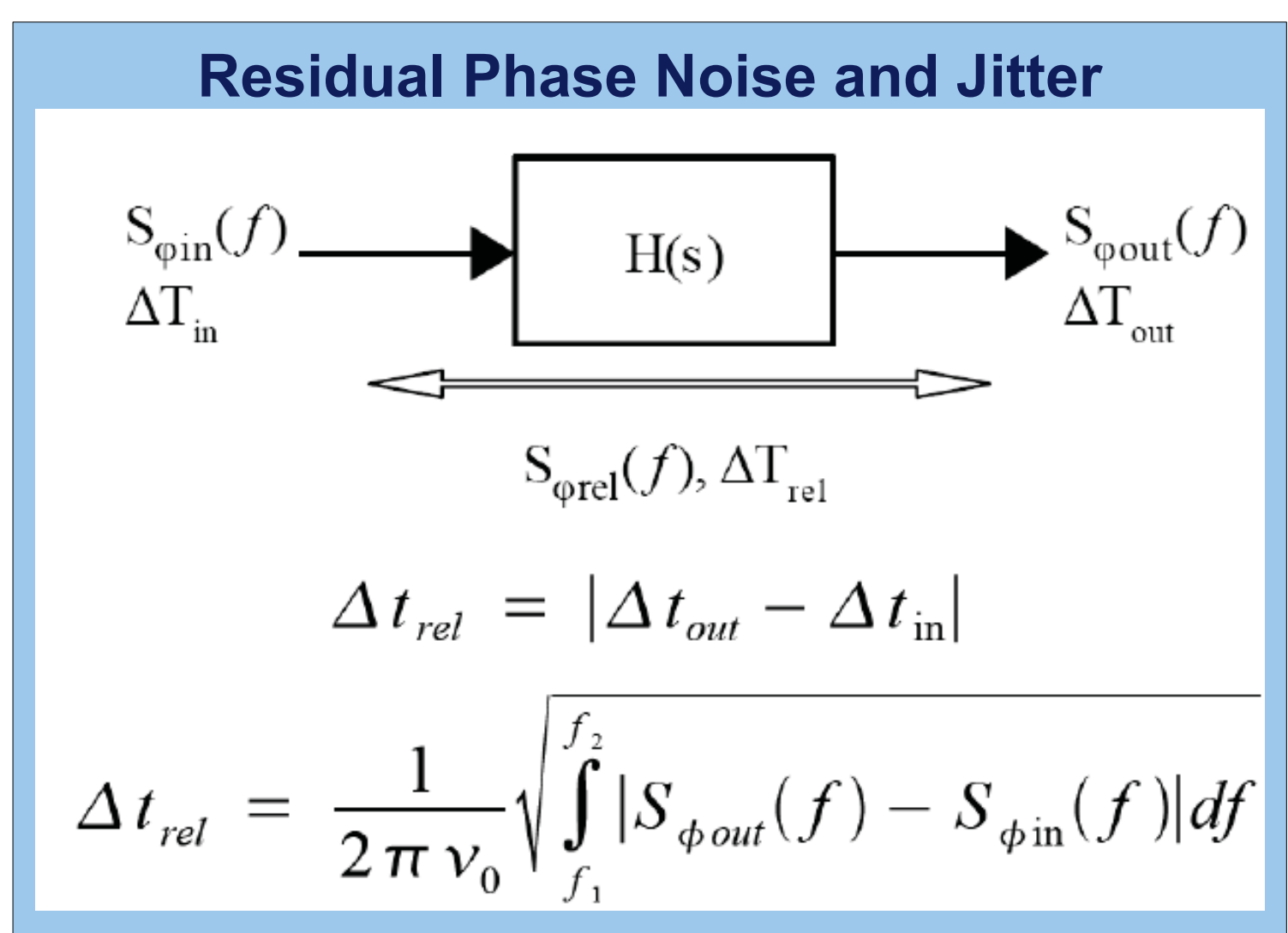




\section{Phase / Timing Jitter}

It is a time domain measure of signal phase instabilities $\phi(t)$

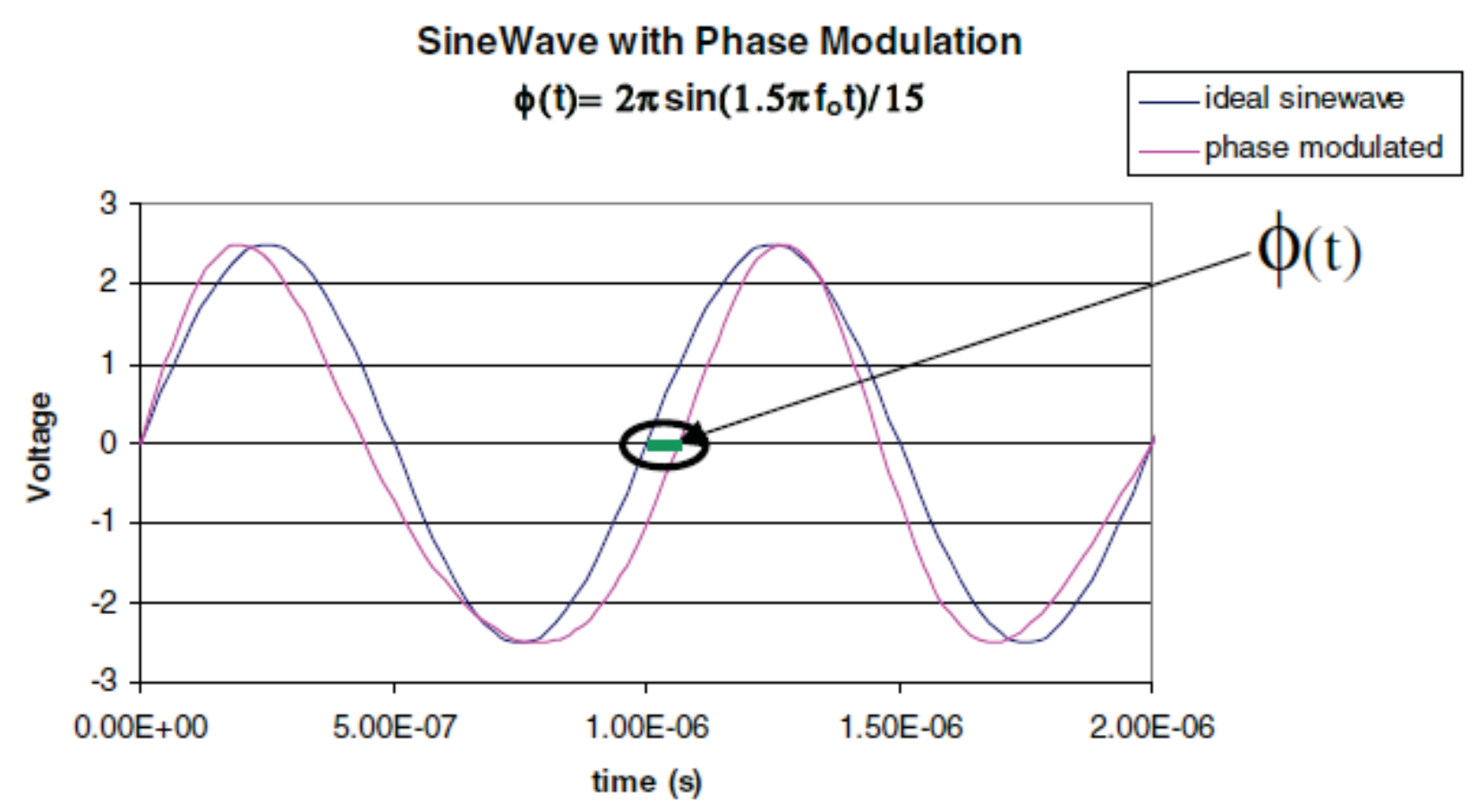

Phase jitter $\phi_{j i t t e r}^{2}$ is calculated in units of radian

Timing jitter $\Delta t_{R M S}$ is calculated in units of seconds RMS. Used frequently with digital signals

Figure source: Corning Frequency Control 


\section{Phase Noise and Jitter Relationship}

Jitter is the integral of $S_{\phi}(f)$ over the Fourier frequencies of application

$$
\begin{aligned}
\phi_{j i t t e r}^{2} & =\int_{f_{1}}^{f_{2}} S_{\phi}(f) d f \\
\Delta t_{r m s} & =\left(\frac{1}{2 \pi v_{0}}\right) \sqrt{\int_{f_{1}}^{f_{2}} S_{\phi}(f) d f}
\end{aligned}
$$

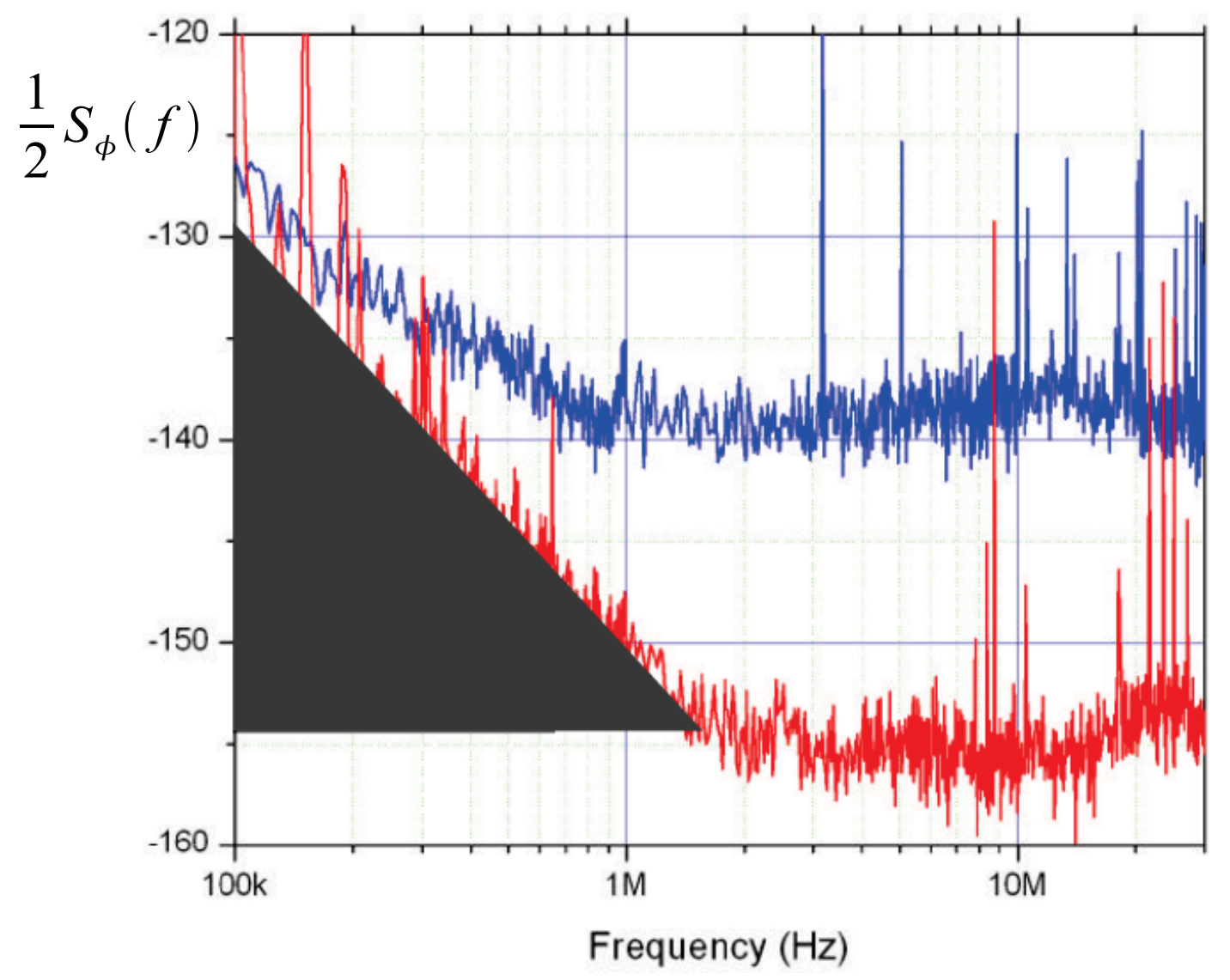




\section{Phase Noise Contributions to Jitter}

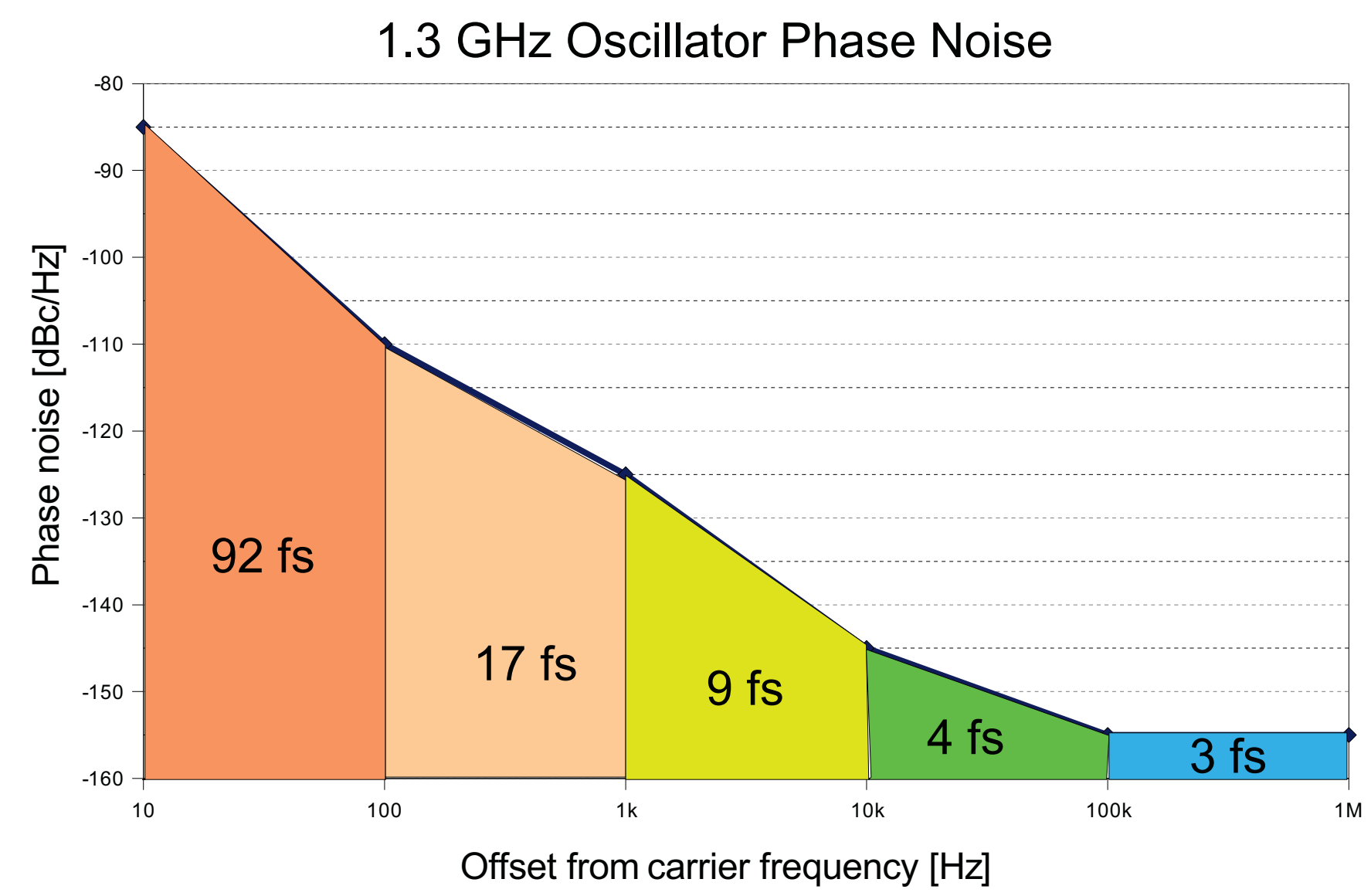




\section{Time Domain Timing Jitter Measurement}

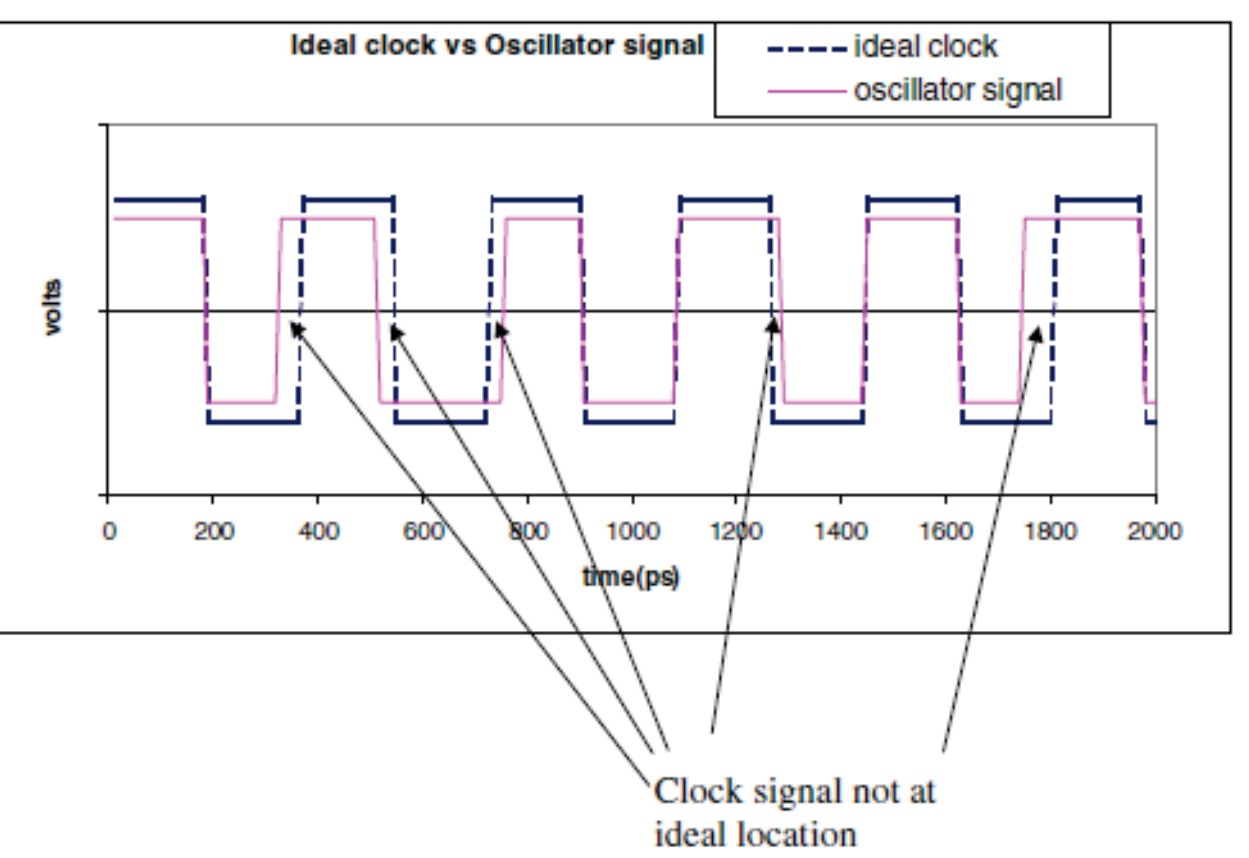

Eye Diagram

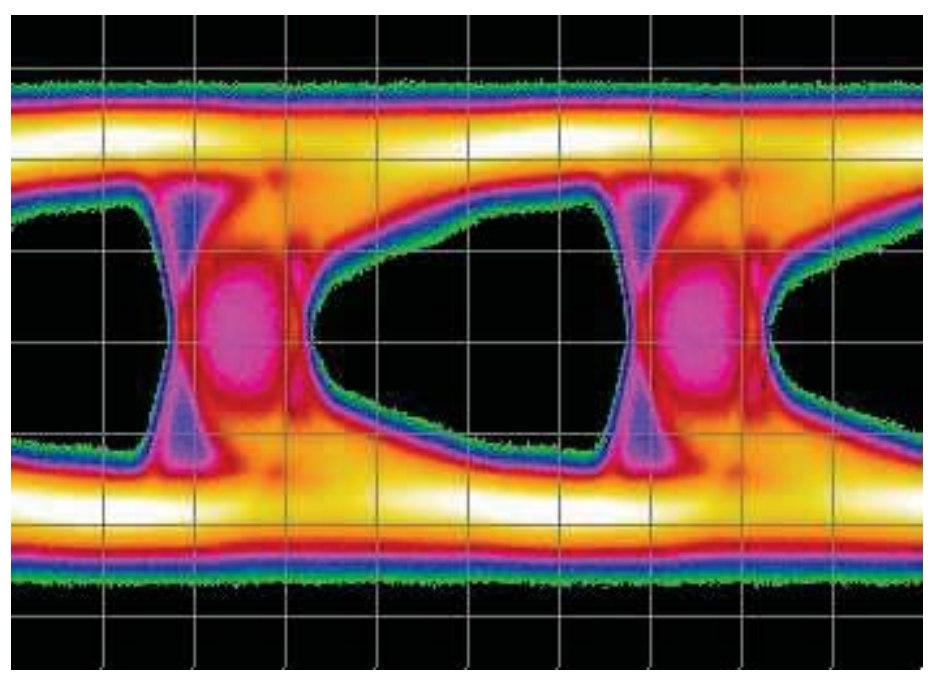

In the time domain the timing jitter is measured with a digital scope 


\section{Generic Synchronization System}

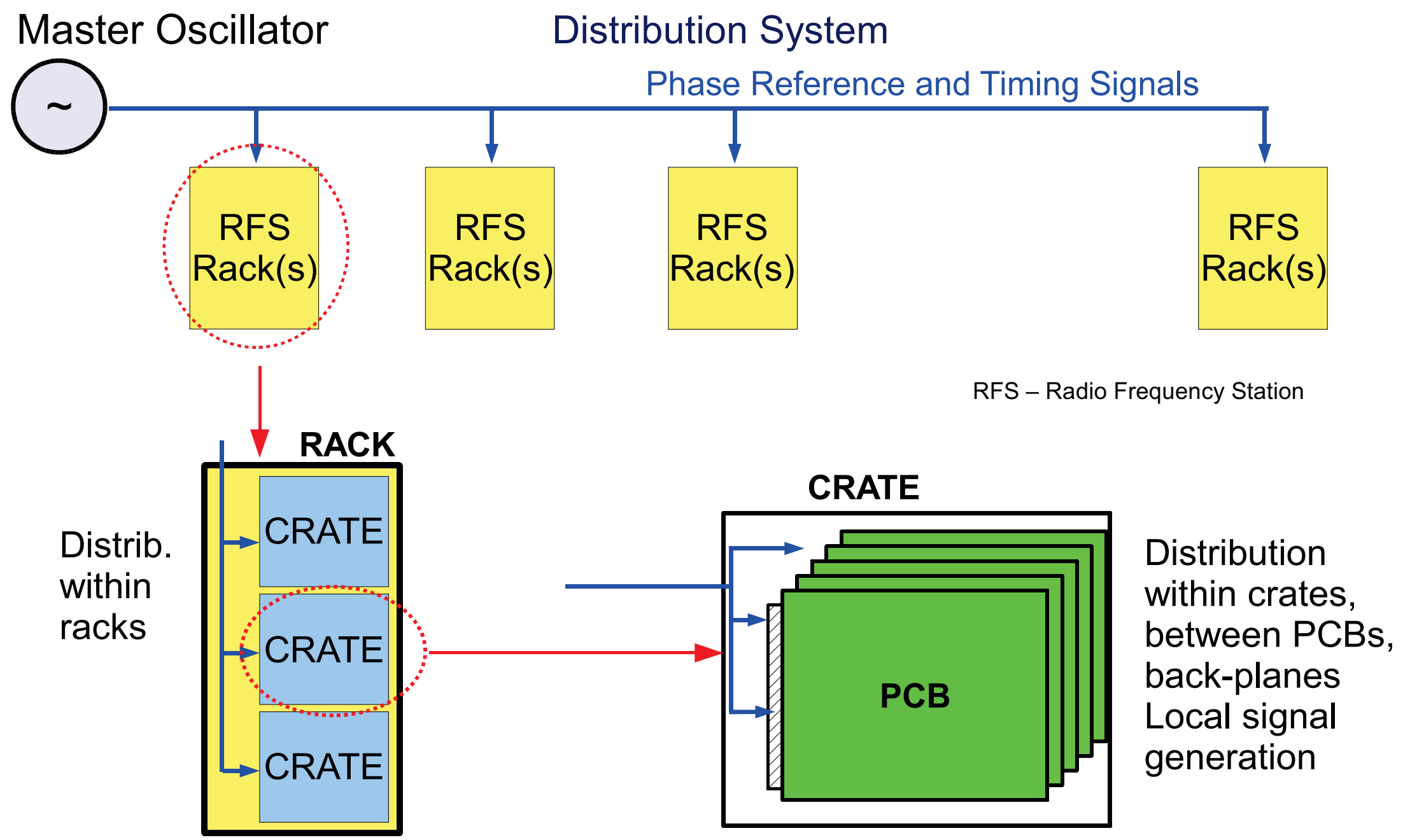




\section{Generic Synchronization System}

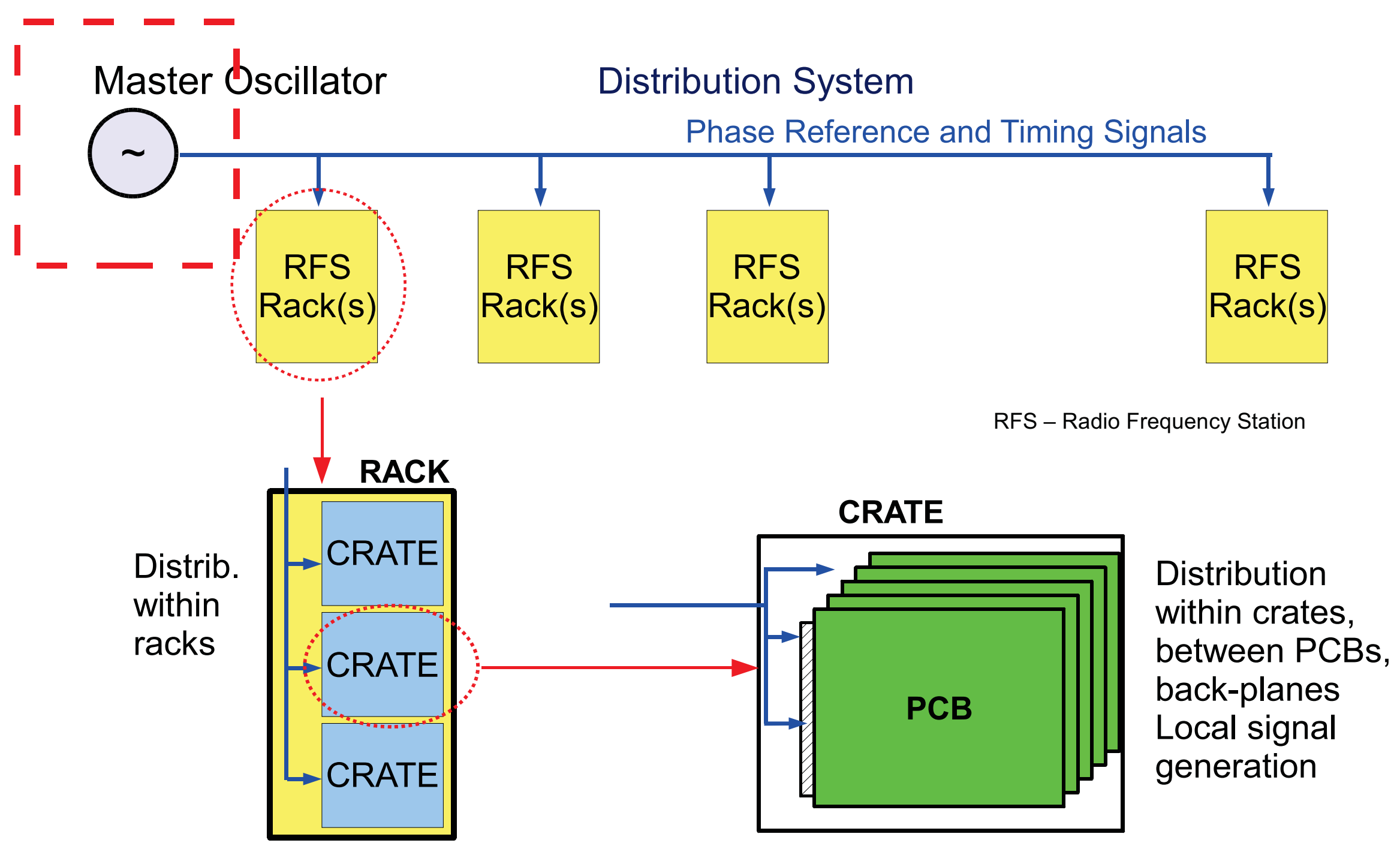




\section{Master Oscillator}

This device is providing the reference signal for the entire synchronization system

\section{Single signal source}

But in practice ... 


\section{Master Oscillator System Example}

\section{The MO System}

But for convenience people call it MO

FLASH "MO" Scheme*

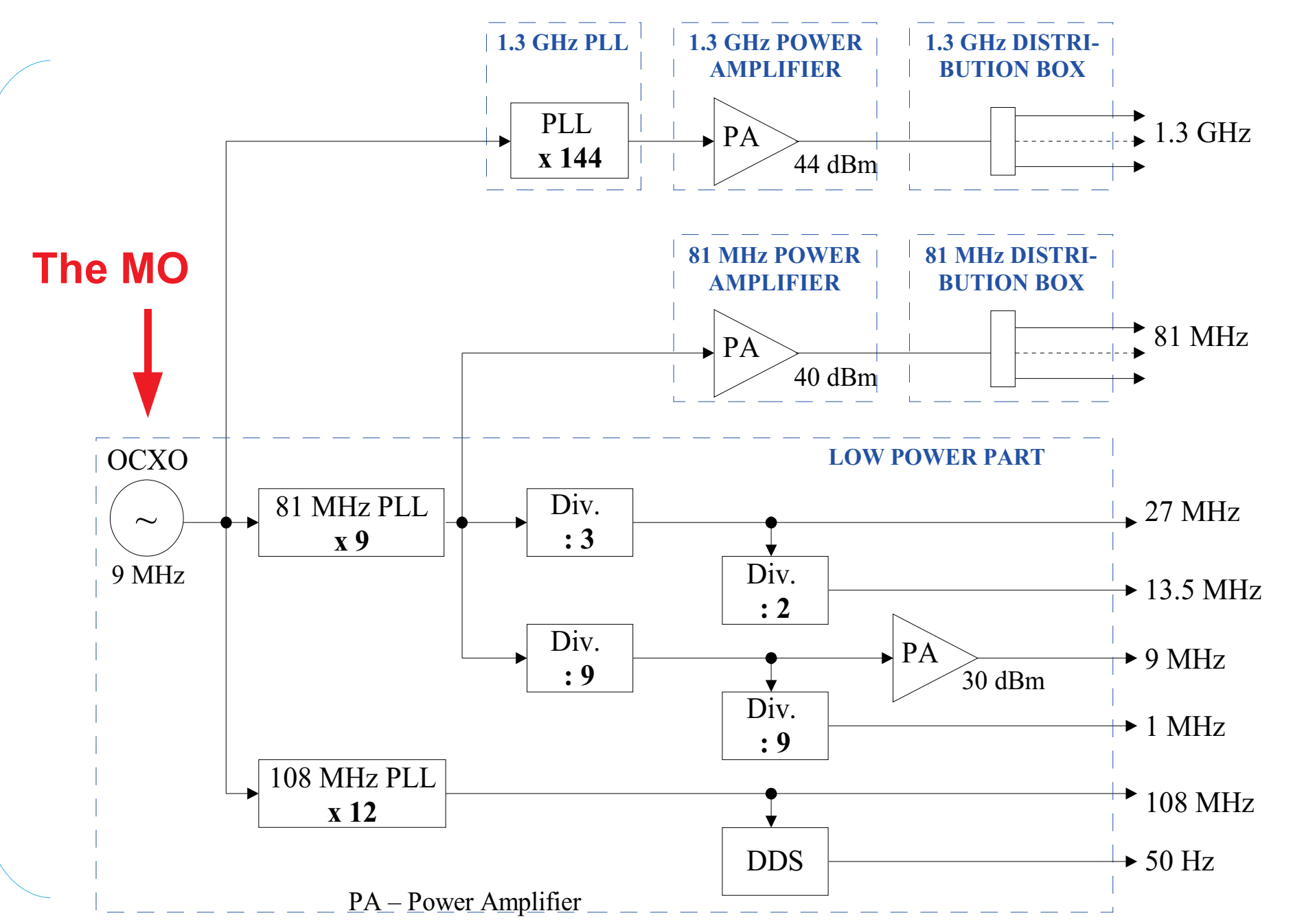

* will be presented in more detail by Henning Weddig 


\section{MO System}

- MO

- Frequency generation scheme

- Signal level adjustment (power amplifiers)

- Splitters and interface to distribution links

- Power supply (very important issue!), sometimes must be unbreakable

- Diagnostics 


\section{Stable Signal Sources}

- Crystal Quartz Oscillators (OCXO) (from $5 \mathrm{MHz}$ to 100 $\mathrm{MHz}$ )

- custom, non-decimal frequencies available

- relatively low price and size

- Atomic Standards

- excellent long term stability

- short term stability worse than for OCXO

- typically $10 \mathrm{MHz}$ output (problem with custom frequencies)

- Relatively expensive

- GPS receiver

- synchronized to $10 \mathrm{MHz}$ atomic standard

- good solution for large machine (several devices may provide good timing)

- sensitive to atmospheric conditions 


\section{Frequency Multiplication and Division}

- Frequency multipliers

- Fixed multiplication value (x2, x4)

- Rather small multiplication factors

- PLL multipliers (synthesizers)

- Phase locking of a VCO to the reference signal

- Flexible choice of multiplication factors

- Proper design allow for minimizing system phase noise

- Frequency dividers

- Usually based on digital counters

- Modern devices offer very low residual jitter values, even as low as $100 \mathrm{fs}$

- Direct Digital Synthesizers (DDS)

- Combinations of units listed above 


\section{PLL Synthesizer}

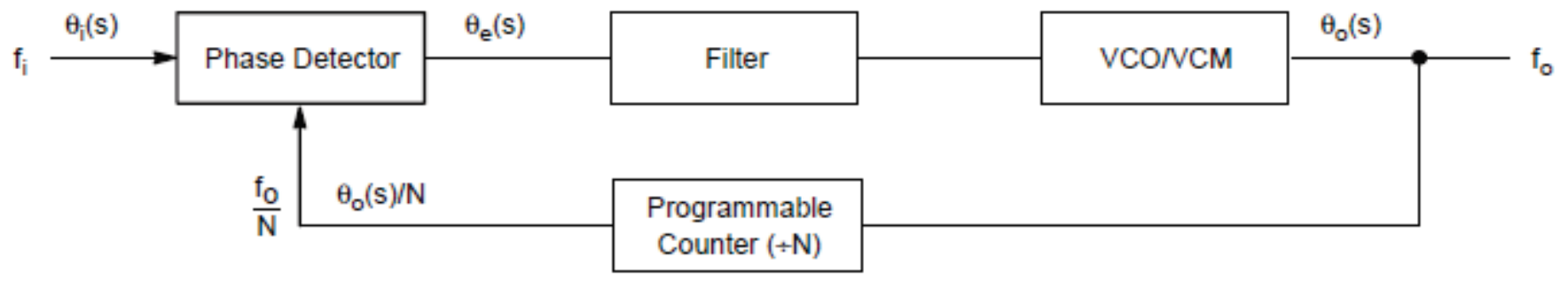

- Phase - locking of a VCO to a reference signal

- Flexibility in selecting output frequency

- Proper selection of PLL components allow for phase noise (jitter) reduction comparing to a standard multiplier

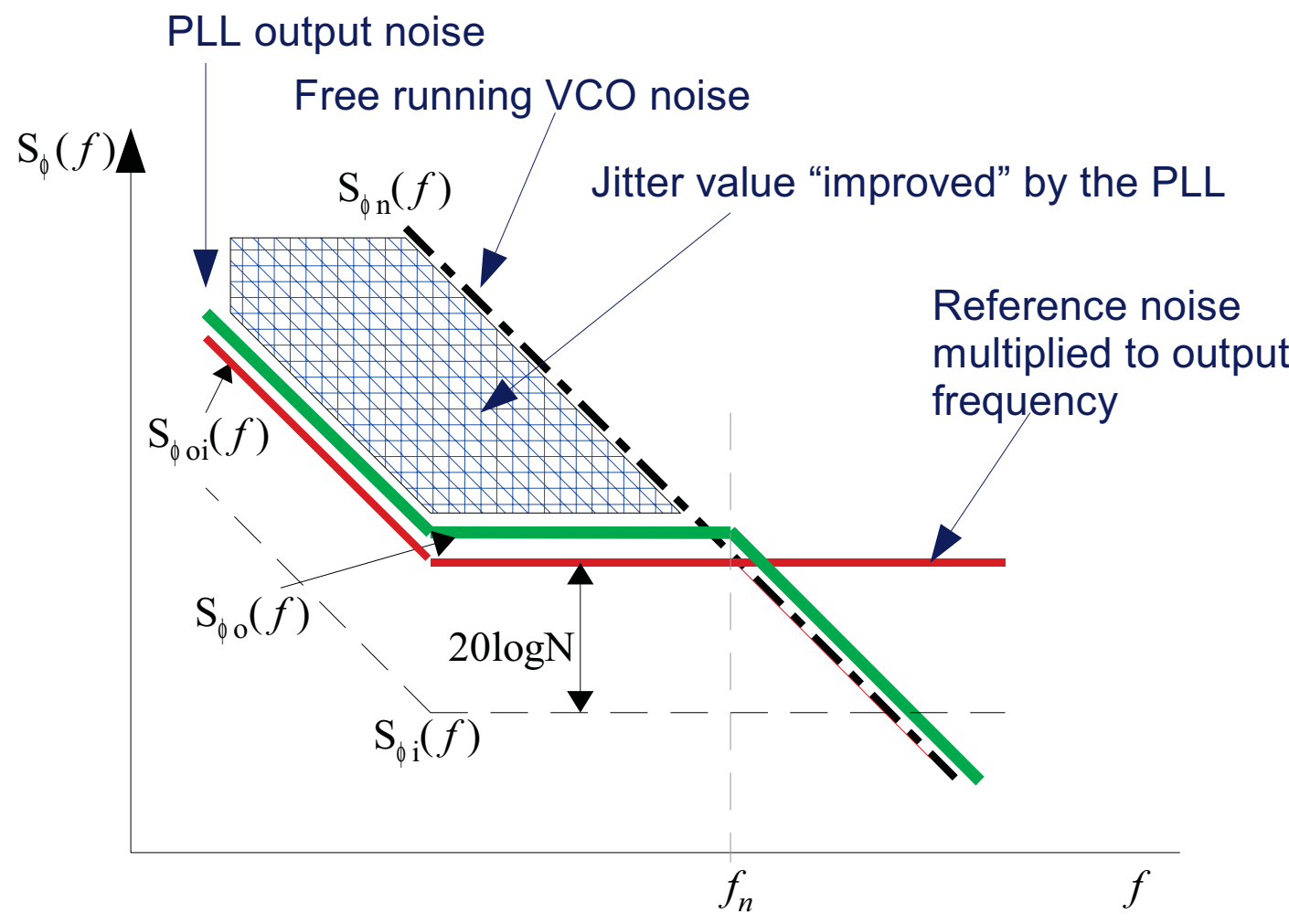




\section{Stable Signal Distribution}

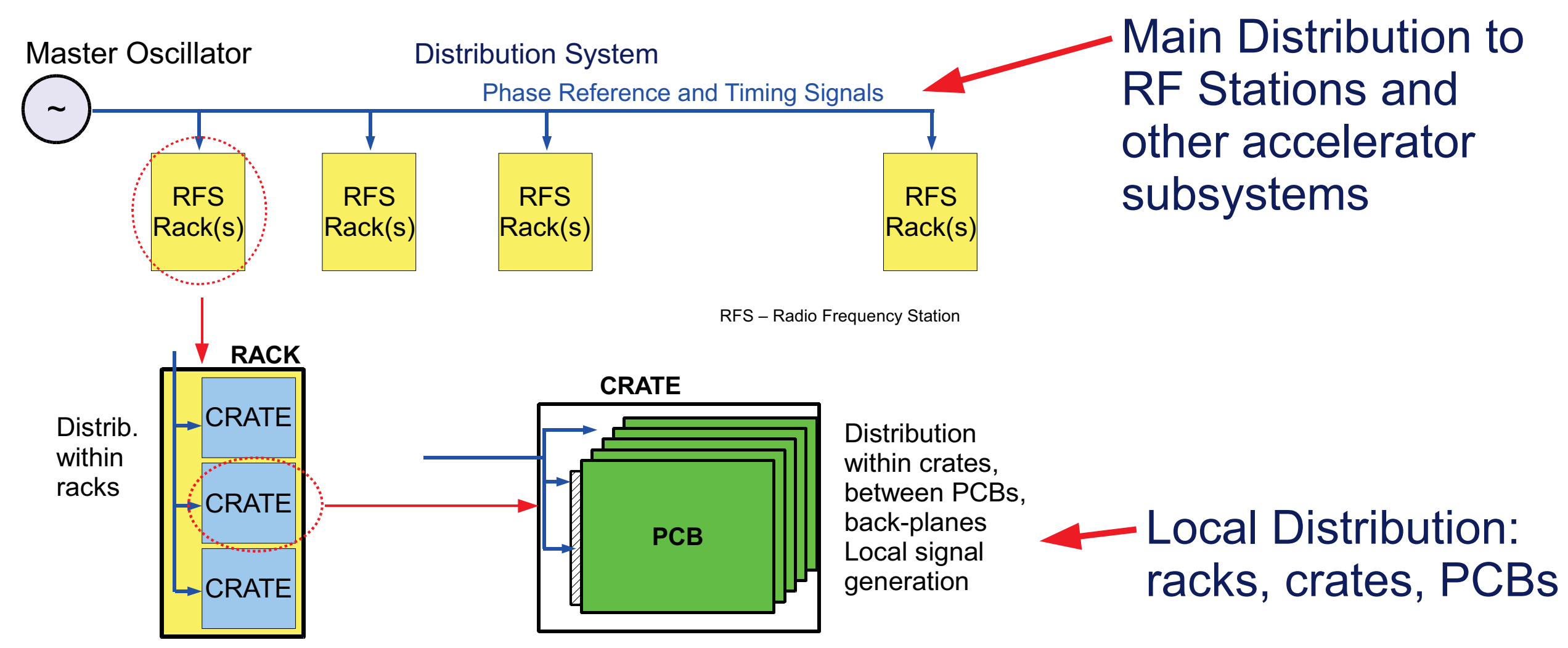

The importance of a local distribution is frequently underestimated Last 2 meters of a poor quality cable exposed to vibrations or a "wrong" track on a PCB can destroy the signal performance achieved over hundreds of meters of distribution! 


\section{Distribution System Issues}

1. System topology:

- Star

- Line with tap points

2. Distribution media type:

- Coaxial cable or waveguide

- Optical fiber

- Air (radio synchronization)

3. Distributed signal type:

- Continuous sine wave

- Pulses used for local oscillator synchronization

- Digital signals (triggers, clocks)

4. Influence on the signal:

- Passive

- Stabilized: e.g. temperature stabilized cable link

- Active: with feedback circuits actively controlling signal phase 


\section{Distribution Media: Cable vs. Optical Fiber}

\begin{tabular}{|c|c|c|}
\hline Parameter & Coaxial & Fiber \\
\hline Attenuation & High & $\begin{array}{c}\text { Low at any RF } \\
\text { frequency }\end{array}$ \\
\hline Distribution distance & short & long \\
\hline $\begin{array}{c}\text { Temperature } \\
\text { coefficient of phase } \\
\text { lenghth }\end{array}$ & $\sim 10^{-5} /{ }^{\circ} \mathrm{C}$ & $\sim 10^{-5 /{ }^{\circ} \mathrm{C}}$ \\
\hline $\begin{array}{c}\text { Need of feedback } \\
\text { controlling phase } \\
\text { drifts }\end{array}$ & YES & YES \\
\hline Price & Relatively high & $\begin{array}{c}\text { Fiber - low but } \\
\text { Tx and Rx high }\end{array}$ \\
\hline
\end{tabular}

The decision not obvious and usually some compromise is needed 


\section{Phase Drifts in Distribution Media}

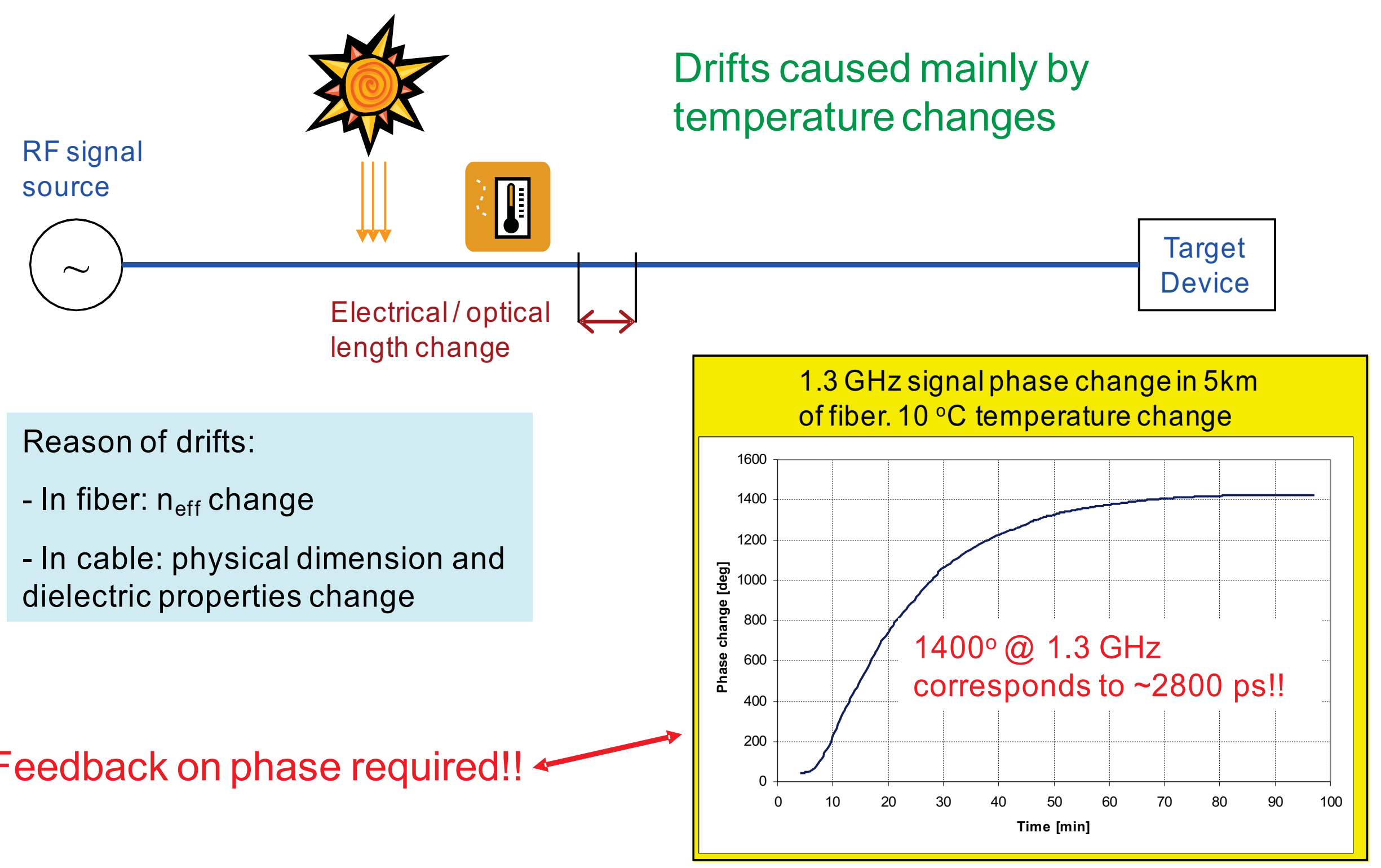




\section{Phase Drifts in Distribution Media (2)}

- There are cables with low temperature coefficient available $\left(0\right.$ to $\left.10 \mathrm{ppm} /{ }^{\circ} \mathrm{C}\right)$ in given temperature range

- Unfortunately, the accelerator temperature does not always fit our needs - temperature stabilization or drift compensation may be required

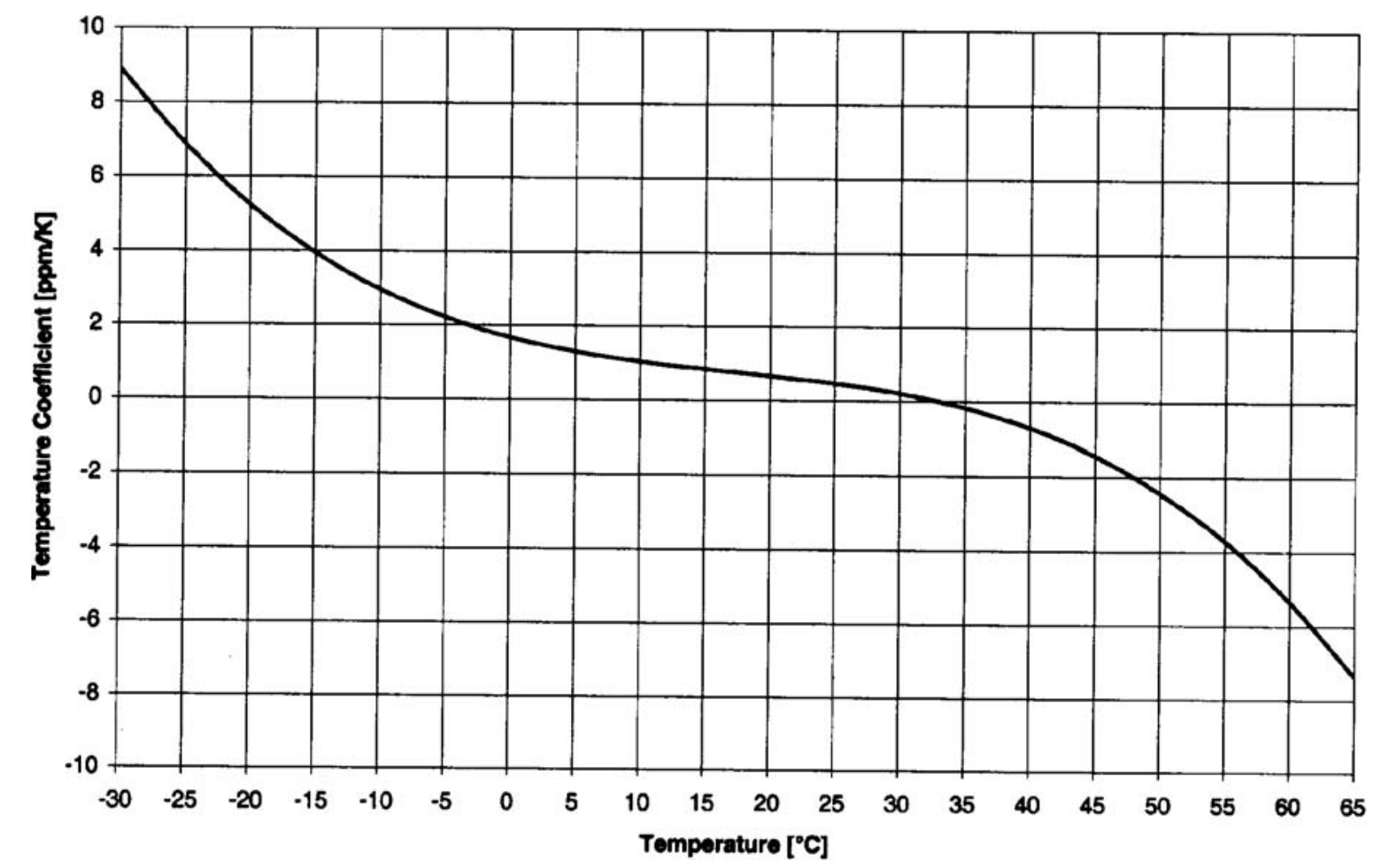

- Good laboratory cables achieve tens to few hundreds of $\mathrm{ppm} /{ }^{\circ} \mathrm{C}$

- Temperature coefficients of poor quality cables reach thousands of $\mathrm{ppm} /{ }^{\circ} \mathrm{C}$ $\rightarrow 1$ meter of such cable inside of a rack can be worse than hundreds of meters of a thick distribution cable! 
- Possible but difficult

- No direct influence on the distributed signal

- Usually realized by a heating tape wrapped around the cable and thermal insulation around

- Space consuming and difficult installation

- Rather for short distances (cost issue) - max. few hundred meters

- Temperature controller parameters must be adjusted very carefully! Even $0.5^{\circ} \mathrm{C}$ temperature variation can cause phase modulation in the cable... 


\section{Active Drift Compensation}

- So called reflectometric method used in many variations for both, fiber and coax cable

- The basic principle: correct for phase drift by measurements of a round-trip time delay changed

- Achieving 100 fs peak stability over several hundred meters is relatively easy

- Optical labs claim the ability to reach single fs! 


\section{Active Drift Compensation Example}

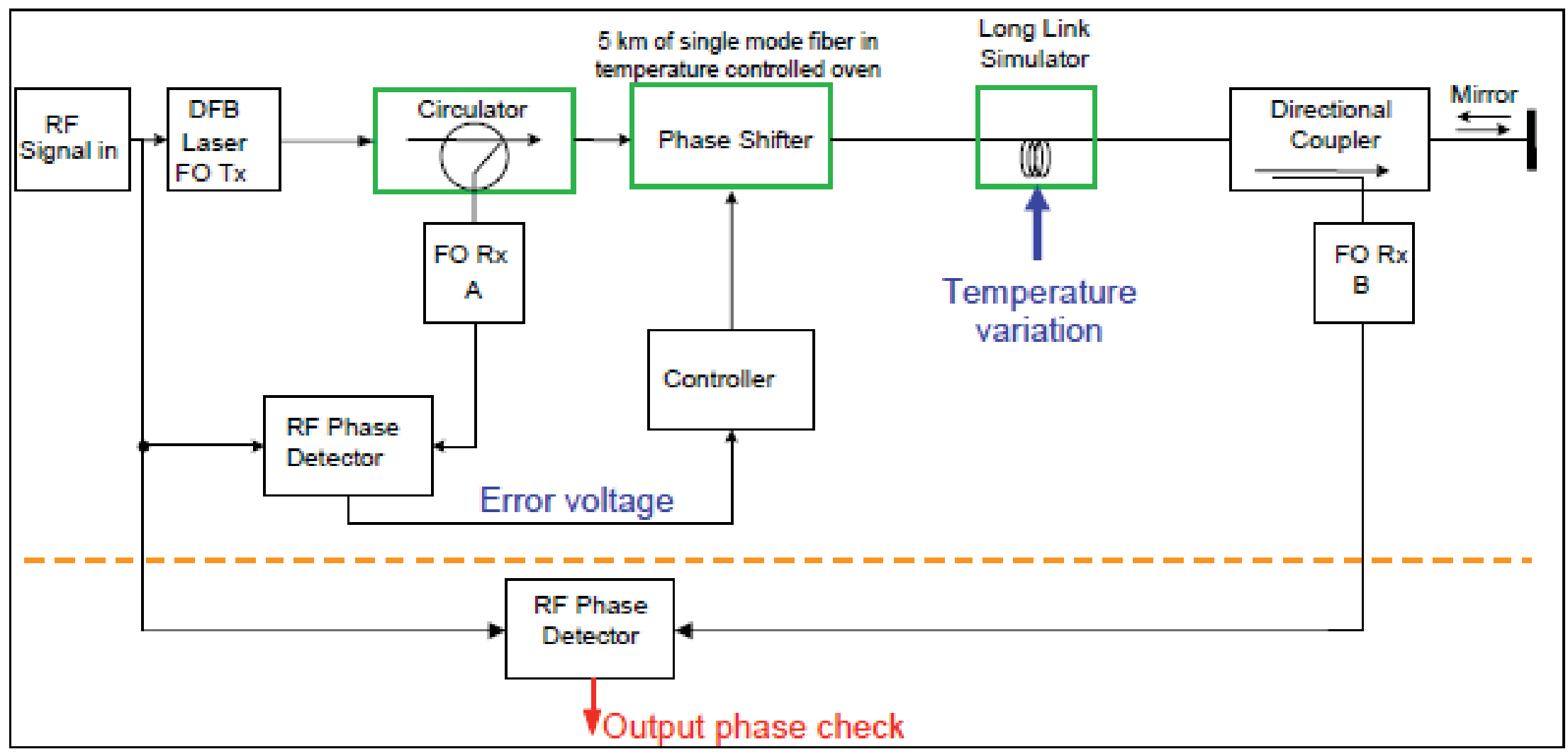




\section{Active Drift Compensation Results}

Measurement performed inside of the climate chamber

$5 \mathrm{~km}$ of fiber used as long link $100 \mathrm{~h}$ measurement duration

ODL position followed temperature induced phase drifts

RESULTS

\begin{tabular}{|l|c|c|}
\hline $\begin{array}{l}\text { Phase } \\
\text { Shifter }\end{array}$ & $\begin{array}{l}\text { Short term } \\
\text { stability [ps] }\end{array}$ & $\begin{array}{l}\text { Long term } \\
\text { stability [ps] }\end{array}$ \\
\hline $\begin{array}{l}5 \mathrm{~km} \text { fiber on } \\
\text { spool }\end{array}$ & 0.8 & 5 \\
\hline ODL & 0.3 & 0.8 \\
\hline
\end{tabular}
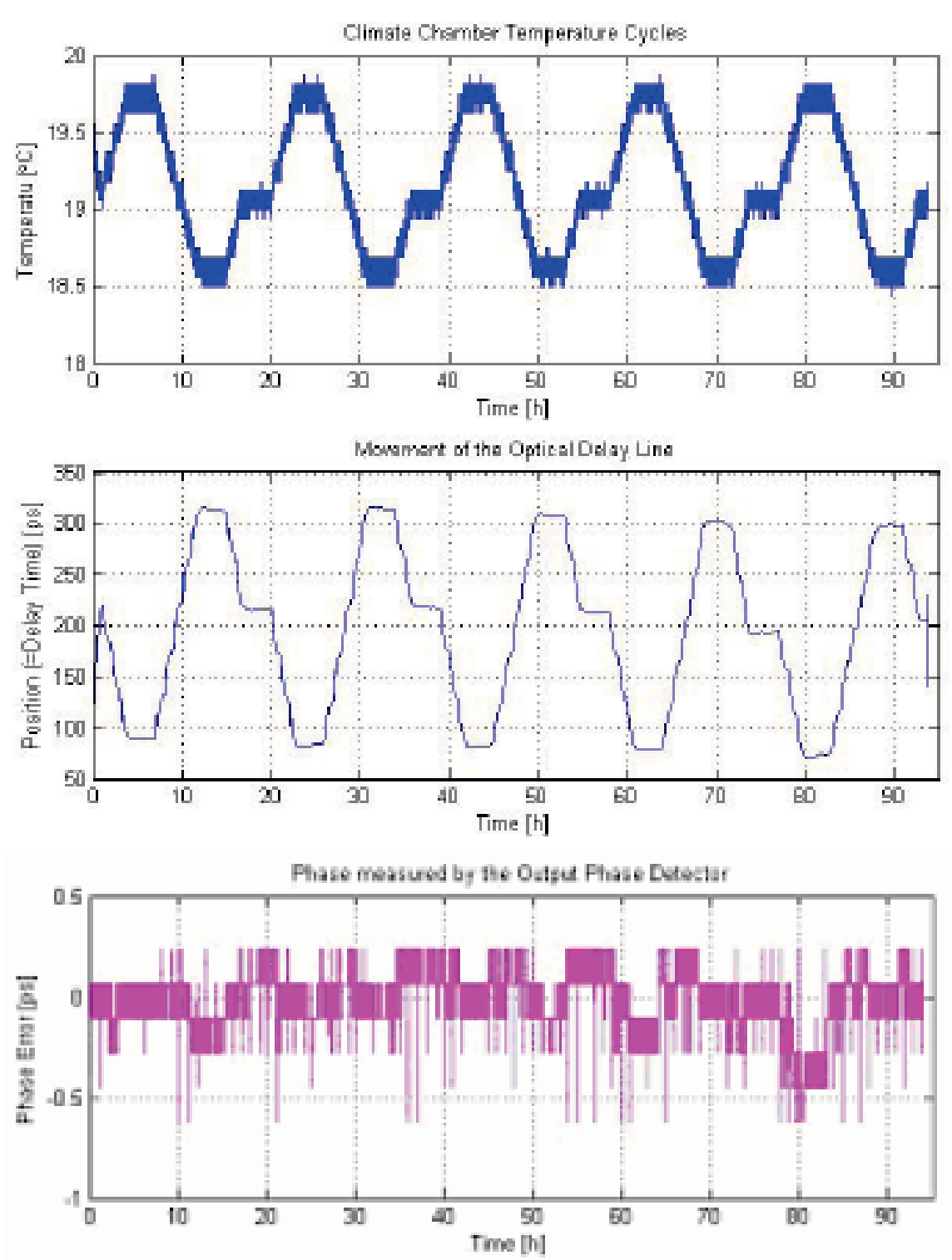


\section{Synchronization System}

Consists of:

- Master Oscillator

- Phase Reference Distribution (for harmonic RF signals)

- Timing System (for clocks and triggers) 


\section{Timing System}

- Mainly devoted to assure synchronization of accelerator subsystems for executing events necessary for accelerator operation

- Distribute signals with coded information about events, time, pulse and bunch numbers

- Clock signals can be extracted of the timing signal. But there is an opinion that ADC clocks should be generated directly

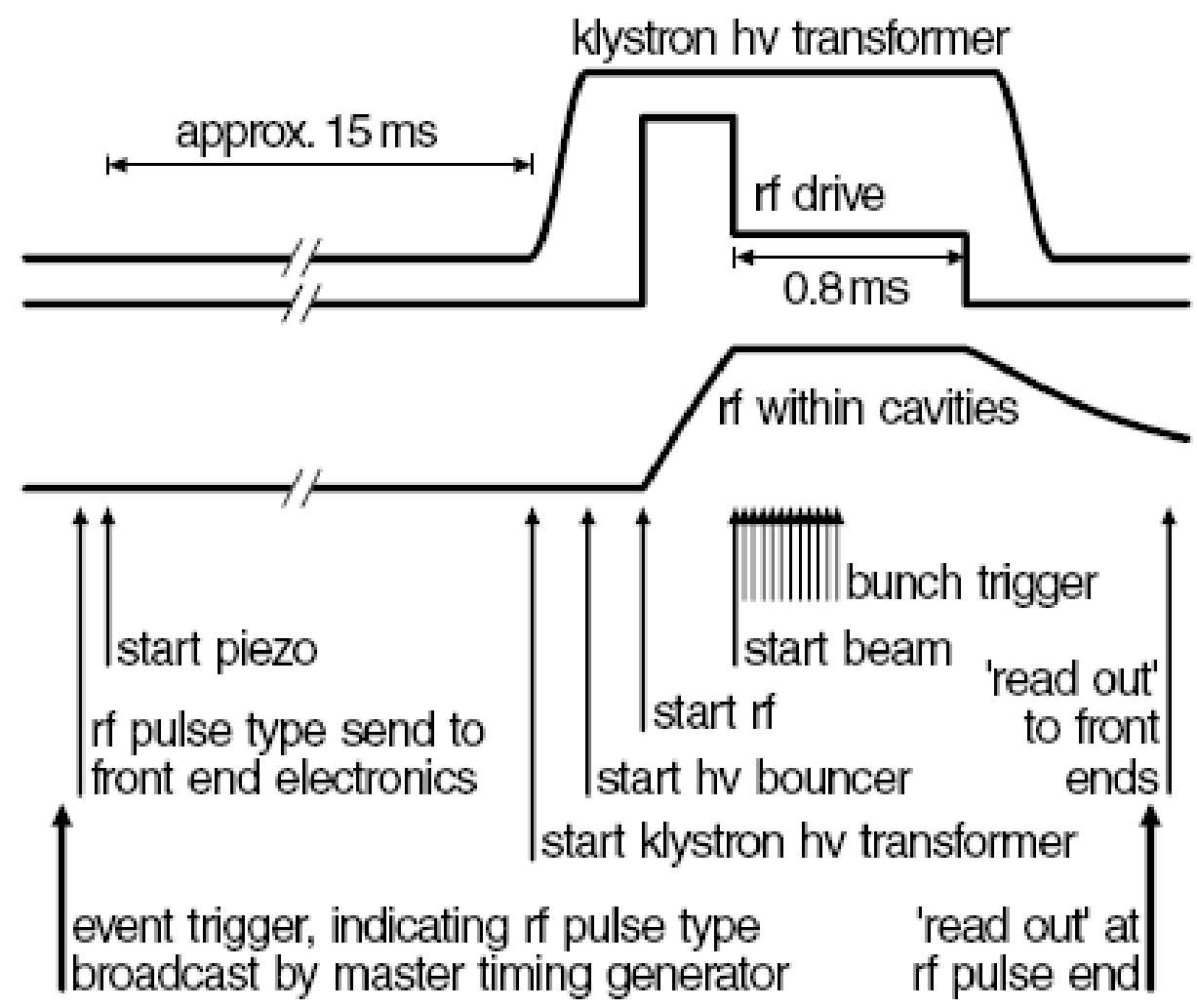
from the MO signal (smaller residual jitter between ADC and DWC signal

- Usually optical signal distribution used. Based on low cost telecom fiber transceivers. 


\section{Timing System Example}

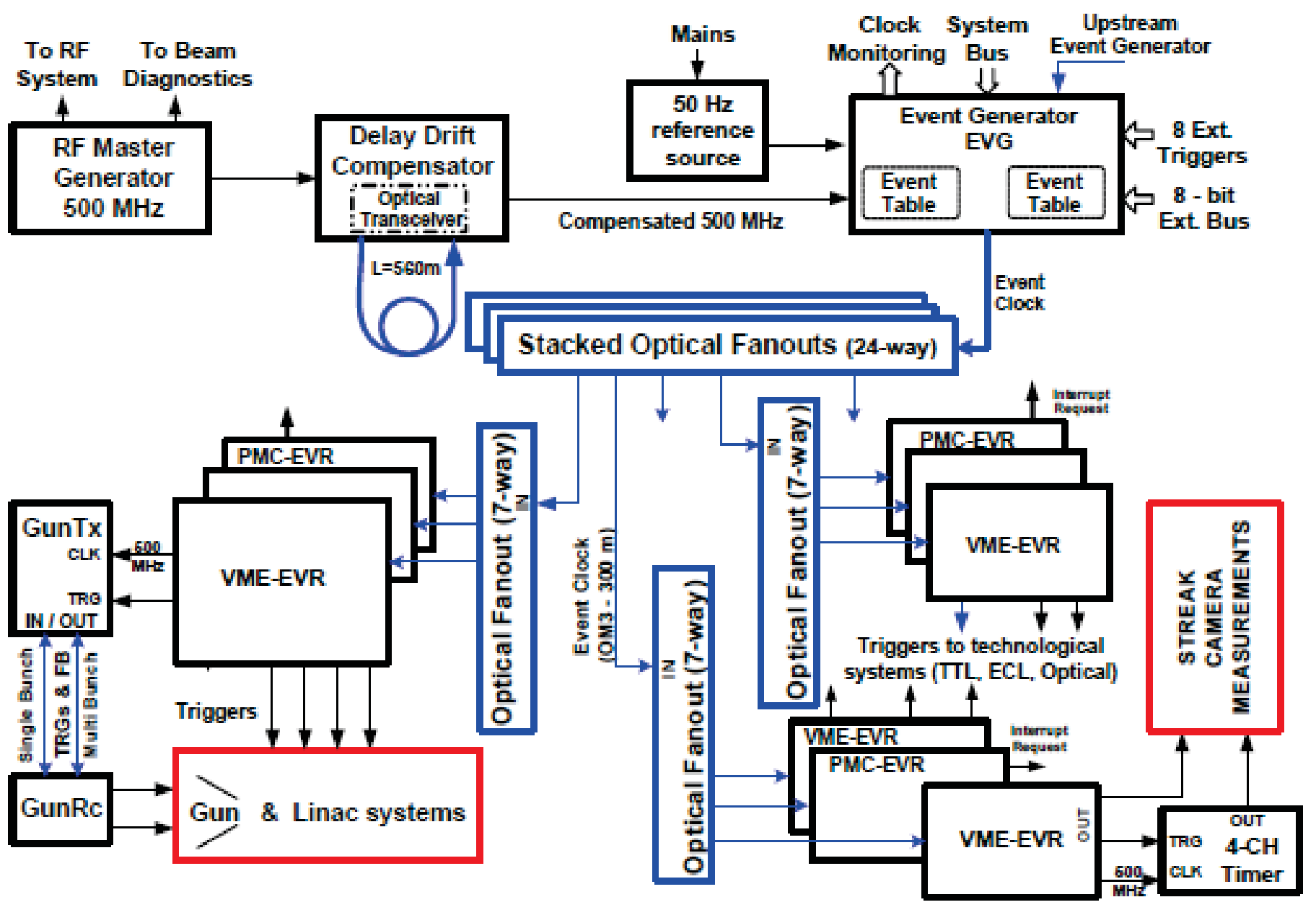




\section{Timing Signals in PCBs and Backplanes}

Seems to be separated topic but:

- We go towards hundred of $\mathrm{MHz}$ differential clocks to be distributed over many boards and backplane inside a crate

- ADC clock parameters become critical for the performance of the entire LLRF system

- Understanding the limitations may help in proper specifying parameters of the synchronization system and save effort and costs 


\section{Diagnostics}

- Good diagnostic system can be very helpful during commissioning and maintenance of the synchronization system

- On-line readout of PLL lock signals, power levels and supply voltage presence will help with localizing potential faults and decrease the accelerator down time

- On-line temperature readout can be used for estimating phase drifts 


\section{Observation}

One of the most difficult issues of a large synchronization system design is collecting user requirements 


\section{Conclusions}

- The design of a synchronization system is a very complex and challenging task

- A lot of expertise of various fields of engineering is required to make a successful design

- Nowadays synchronization systems go to high complexity and extreme accuracy of measured by single fs

- Many new solutions must be worked out to fulfill the newest requirements 
Thank You for Your Attention! 